\title{
Enhancing Students' Conceptual and Procedural Knowledge Using a New Teaching Approach of Linear Equations Based on the Equivalence Concept
}

\author{
Safâ Qetrani ${ }^{1 *}$, Salek Ouailal ${ }^{2}$, Naceur Achtaich $^{1}$ \\ ${ }^{1}$ Laboratory of Analysis, Modelling and Simulation (LAMS), Hassan II University of Casablanca, B.P 7955, Sidi Othman, \\ Casablanca, MOROCCO \\ 2 The Regional Center for Education and Training Professions in Agadir, MOROCCO
}

Received 15 September 2020 - Accepted 11 March 2021

\begin{abstract}
Conceptual understanding is one of the main concerns of mathematics education. Numerous research have discussed student understanding of algebraic concepts, linear equations in particular. This research was drawn upon in order to develop a new approach for teaching and learning linear equations based on the equivalence concept, one that aims to improve students' algebraic thinking. The purpose of this paper is to evaluate the effectiveness of the equivalence approach teaching method over the traditional teaching method in improving students' flexibility and minimizing their errors in solving equations. The sample consisted of 61 junior-high-school Moroccan students that were assigned randomly to two groups: the control group and the experimental group. Within the posttest-only control group experimental design, the MannWhitney $\mathrm{U}$ test was used to compare differences in posttest scores between the two independent groups. Findings indicate that the equivalence approach teaching method was effective in enhancing students' flexibility and in minimizing two categories of errors: conceptual and transformations errors.
\end{abstract}

Keywords: conceptual knowledge, procedural knowledge, linear equations, equivalence approach, flexibility, errors categories

\section{INTRODUCTION}

For years research on mathematics education has focused on students' conceptual understanding of algebra. They provided evidence that school level algebra usually emphasizes procedural skills over conceptual understanding for solving algebraic tasks. Thus, students are more apt to use strategies involving algebraic calculation with a superficial knowledge of procedures and without understanding the implicit concepts behind. Therefore, algebraic reasoning, in particular relational thinking and equivalence, are not the first priority in algebra classes (Crooks \& Alibali, 2014; Kieran, 1981).

Many studies have discussed teaching methods that may help students to master both procedural and conceptual algebraic knowledge; two competencies that allow students to be more flexible, less susceptible to making errors, and better able to explain and justify their works. For linear equations, studies show a strong correlation between the students' understanding of the equivalence concept and their giving correct reasons for their decisions in addition to other measures of conceptual understandings of algebra. Studies recommended that it is needed "to directly teach the concept of equivalent equations. It is not sufficient to teach equivalence merely as part of the discussion of procedures for solving equations." (Kieran,1981; Steinberg, Sleeman, \& Ktorza, 1991). Building on these studies, a new approach is proposed that is based on the concept of equivalence for teaching linear equations, the equivalence approach (EA). It is believed that this approach can improve students' algebraic reasoning and increase their likelihood of success in the study of advanced mathematics. The equivalence approach teaching method emphasizes both the conceptual knowledge and the procedural skills related to linear equations. It is based on two concepts: the equivalence of algebraic expressions and the equivalence of 


\section{Contribution to the literature}

- This study presents a new approach based on the equivalence concept for teaching linear equations.

- This study provides support for research which confirmed that only the integration of both conceptual and procedural knowledge could improve students' algebraic thinking and procedurals skills.

- Findings contribute to the understanding of the effect of the equivalence approach and the traditional teaching method on the students' flexibility in solving linear equations and the errors made in solving equations reducible to linear equations.

equations. The first objective of the EA is to make students understand: the different meanings of variables and the equal sign, the algebraic expression as an object, and the equivalence of algebraic expressions from a numerical and an algebraic view. The second objective is about linear equations, where the equation is introduced as equality between two algebraic expressions, and the equivalence of equations is explained using the equality properties. The third main objective is to teach students how to solve linear equations using the equivalence concept. Thus, this paper focused on the designing the EA teaching module and then testing its effectiveness in enhancing students' flexibility and making them more performant in preventing errors in solving equations. In doing so, the following research questions were addressed: How does the equivalence approach increase students' conceptual and procedural understanding? Could the equivalence approach help students to become more flexible solvers? To what extent does the equivalence approach help students to correct their misconceptions and prevent them from making errors in solving equations?

\section{CONCEPTUAL AND PROCEDURAL KNOWLEDGE}

Conceptual knowledge can be defined as the explicit or implicit comprehension of the concepts, operations, and relations that cover a domain. Its development is achieved by the construction of interrelationships between pieces of information that already have been stored in memory or between an existing piece of knowledge and one that is newly learned (Hiebert \& Lefevre, 1986; Rittle-Johnson \& Alibali, 1999). The concept of equivalence is the main concern of studies that sought to improve conceptual knowledge in the domain of algebra, in particular linear equations (RittleJohnson \& Alibali, 1999). On the other hand, procedural knowledge was defined as knowledge of algorithms for completing mathematical tasks, as a surface knowledge of the symbols and syntax of mathematics, and as the knowledge of the operations and these conditions of use (Byrnes \& Wasik, 1991; Hiebert \& Lefevre, 1986; RittleJohnson \& Alibali, 1999). The procedural knowledge of equations that have been assessed in this paper refers to the students' knowledge for solving equations.

By analyzing the impact of conceptual knowledge on procedural knowledge, research has provided evidence that conceptual understanding leads to the generation of procedures and adaptation of them for solving new tasks (Byrnes \& Wasik, 1991). Other authors have confirmed that students who have acquired a conceptual understanding of mathematical ideas have demonstrated a procedural fluency for the treatment of mathematical tasks (Heibert \& Lefevre, 1986). Procedural fluency means the knowledge of when and how to use acquired procedures flexibly, accurately, and efficiently (Kilpatrick, Swafford, \& Findell, 2001). For example, Perry's (1991) study demonstrated that increasing students' conceptual knowledge of mathematical equivalence leads to the generation of appropriate procedures for solving equivalence problems.

According to this research, students' difficulties in solving equations can be overcome if the traditional teaching method based on procedural instructions is replaced with the equivalence approach teaching method that combines conceptual understanding and procedural skills. Therefore, the effect of the EA teaching method on students' flexibility in solving equations, and whether it could make students less likely to make critical errors, was examined.

\section{Flexibility}

Based on Star and colleagues studies, flexibility was defined as (a) knowledge of multiple strategies to solve a problem and (b) knowledge of the most efficient strategy according to the problem's particularities (Star, 2005; Star \& Rittle-Johnson, 2008; Star \& Seifert, 2006). They mean by strategy a multi-step procedure for solving a problem. Therefore, a flexible solver should be able to switch between different strategies, and especially be able to select the most appropriate, efficient, and optimal strategy, meaning that the strategy which involves the fewest steps and the least effort for execution. Star and Seifert (2006) discussed another competence related to flexibility, named the invention, which involves the use of procedures in non-standard ways for solving unfamiliar problems efficiently. Thus, the National Council of Teachers of Mathematics insisted on the importance of conceptual learning in preventing the rote execution of memorized algorithms and practicing tedious computations without understanding. At the same time, the importance of developing flexibility as a principal component of procedural fluency (NCTM, 2001) was underlined. Studies confirmed that the learning of procedures 
should be connected to conceptual knowledge in order to have a deep knowledge of procedures and to be able to use them appropriately (Baroody, Feil, \& Johnson, 2007; Hiebert \& Carpenter, 1992). However, Star (2005) argued that procedural knowledge is not necessarily related to rote memorization and can be taught in a way that leads to flexibility. In this study, the view of researchers who believed that only the integration of conceptual and procedural knowledge could develop flexibility in solving problems (Baroody \& Dowker, 2003) was adopted.

The literature on flexibility provides many suggestions about instructional interventions that may help students to promote their flexibility. The following are some examples. Blöte and colleagues (2001) examined the effects of two different instruction programs on 206 young students' flexibility. The students that received an instructional program that emphasized conceptual understanding with procedural skills showed more flexibility than those who received a program based on the acquisition of standard procedures. For the same reason, Star and Seifert (2006) studied the impact of an instructional intervention on students' flexibility for solving equations. Thus, treatment students were invited to re-solve a preworked problem using a different ordering of transformations, whereas control students solved isomorphic problems. As a result, the treatment students were more likely to use multiple strategies and to invent in their solutions. Similarly, Rittle-Johnson and Star (2007) examined an instructional approach that compared alternative solution strategies for solving equations used by the treatment group, while the control group studied sequentially the same solution methods of isomorphic problems. The findings showed that the treatment groups made greater gains in procedural knowledge and flexibility.

In conclusion, the first hypothesis of this paper is that using the equivalence approach over the traditional teaching method will contribute significantly to improving students' skills to use multiple strategies for solving linear equations and choosing the strategies that are most innovative and efficient.

\section{Errors Categorization}

Making errors is part of the learning process. Some students' errors are due to carelessness, but most of those errors are persistent and occur many times, which is why they are considered "error patterns" (Riccomini, 2016). Li (2006) emphasized the need to distinguish between errors, bugs, and misconceptions. In fact, errors are wrongly answered problems, bugs are faulty algorithms that generate answers and change under different problem contexts, and misconceptions, which are difficult to change, are students' misunderstanding of concepts and the conceptual bases of errors and bugs (Chi, 2005; Li, 2006). With regards to the equations, many studies confirmed that students' errors in solving equations $\mathrm{A}=\mathrm{B}$ are mainly attributed to two misconceptions: the misunderstanding of "the equal sign" as "to do something", and the misunderstanding of the expressions $\mathrm{A}$ and $\mathrm{B}$ as a process rather than an object (Li, 2006; McNeil \& Alibali, 2005). In the same context, Sfard and Linchevski (1994) maintained that the transition from process-oriented thinking to objectoriented thinking of concepts helps students to prevent error patterns. On the other hand, Sleeman (1984) confirmed that even though students applied the correct procedures for solving the equations, they might not understand the rationales and concepts behind these procedures. That creates a major problem for students, especially when the proposed equations are complex and not already known.

Based on these studies, the second hypothesis of this paper is that using the equivalence approach over the traditional teaching method will contribute significantly to minimizing the error patterns made by students when solving unfamiliar equations.

To better analyze and understand the nature of the common errors committed by students, a categorization of errors should be in place. In this article, an errors' typology proposed by many studies was adopted. This typology is that errors can be narrowed down to three categories: Conceptual Errors (CE), Procedural Errors (PE), and Factual Errors (FE). These errors are principally related to misconceptions or a lack of knowledge or skill. Otherwise, there exists another type of error cited in these studies called Carelessness Errors (CRE) which are due to fatigue, impulsivity, or lack of concentration (Brown \& Skow, 2016; Riccomini, 2014).

Conceptual errors were defined as errors that "occur when a student holds misconceptions or lacks understanding of the underlying principles and ideas related to a given mathematical problem" (Brown \& Skow, 2016). Procedural errors, that overlap with conceptual errors, occur when students solve a problem following incorrect steps or rules. For the factual errors, they occur when students do not master information related to mathematics facts (e.g., digit and sign identification, counting, calculation, vocabulary, formulas).

In this study, the errors' categorization was customized to make it effectively and purposefully adapted to the needs of the study. The errors' categorization should be, on the one hand, applicable to errors committed by students on solving equations and, on the other hand, indicative and targeted so that we can confirm or reject the second hypothesis. See the section on Data Analysis for more details.

By reviewing students' answers and identifying error patterns, it was noticed that many students made neither errors in the algorithms followed for solving the equations nor calculation errors. However, they did not 
Table 1. Errors' categorization, description, and examples

\begin{tabular}{|c|c|c|}
\hline Category of errors & Description & Examples \\
\hline $\begin{array}{l}\text { Conceptual Errors } \\
\text { (CE) }\end{array}$ & $\begin{array}{l}\text { They occur when a Student does not respect the } \\
\text { equivalence condition of the equations either by } \\
\text { multiplying or simplifying by zero (algebraic } \\
\text { expressions that cancel for some values) or by replacing } \\
\text { the algebraic expression on one side of the equation } \\
\text { with another nonequivalent expression. }\end{array}$ & $\begin{array}{l}\text { - } \frac{A(x)}{B(x)}=\frac{C(x)}{D(x)} \text { becomes } A(x) D(x)=B(x) C(x) \\
\text { (The expression } B(x) \text { and } D(x) \text { equal zero for } \\
\text { some } x \text {-values) } \\
\text { - } \frac{A(x) B(x)}{A(x)}=0 \text { becomes } B(x)=0 \\
\text { (The expression } A(x) \text { equals zero for some } x \text {-values) }\end{array}$ \\
\hline $\begin{array}{l}\text { Transformation } \\
\text { Errors (TE) }\end{array}$ & $\begin{array}{l}\text { They occur when a student applies a wrong } \\
\text { transformation from the right side of the equation to the } \\
\text { left side or inversely. }\end{array}$ & $\begin{array}{l}\text { - } a x=0 \text { becomes } x=-a \\
\text { - } a x=b \text { becomes } x=b-a \\
\text { - } a x+b=a \text { becomes } x+b=1\end{array}$ \\
\hline $\begin{array}{l}\text { Expressions } \\
\text { Manipulation Errors } \\
(\mathrm{MEE})\end{array}$ & $\begin{array}{l}\text { They occur when a student applies a false rule to } \\
\text { modify an algebraic expression, and they are related to } \\
\text { students' problems with fractions, simplification, } \\
\text { factorization, and expanding. }\end{array}$ & $\begin{array}{l}\text { - The expression } a(b+c)-a \\
\text { becomes }(b+c) \\
\text { - The expression } \frac{a+b}{c+d} \text { becomes } \frac{a}{c}+\frac{b}{d}\end{array}$ \\
\hline Factual Errors (FE) & $\begin{array}{l}\text { They occur when students make a numerical } \\
\text { computation error or use an incorrect formula. }\end{array}$ & $\begin{array}{l}\text { - } 3 x-4 x \text { becomes } x \\
\text { - In using the quadratic formula: } x=\frac{-b^{2}+\sqrt{\Delta}}{2 a}\end{array}$ \\
\hline $\begin{array}{l}\text { Carelessness Errors } \\
\text { (CRE) }\end{array}$ & $\begin{array}{l}\text { They occur when students are not attentive and careful } \\
\text { during the equation's solving process. }\end{array}$ & $\begin{array}{l}\text { - Copy the equation incorrectly } \\
\text { - Forget the minus sign }\end{array}$ \\
\hline
\end{tabular}

respect the equivalence condition of the equations either by multiplying or simplifying by zero (algebraic expressions that cancel for some values) or by replacing the algebraic expression on one side of the equation with another non-equivalent expression. Therefore, this may lead to having solutions that are forbidden values or losing solutions. We considered these errors as conceptual errors because they are directly linked to a misunderstanding of the equivalence concept. Concerning the procedural errors, we have differentiated between Transformation Errors (TE) and Errors in the Manipulation of algebraic Expressions (MEE). Thus, the transformation errors are errors due to the incorrect performance of the equation's transformation step by wrongly moving an expression from one side of the equal side to the other side. Otherwise, the error is in the manipulation of algebraic expressions (MEE) when the student applies a false rule to deal with algebraic expressions on one side of the equation, for example, the error may be in the expanding rules (e.g., $\left.(a+b)^{2}=a^{2}+b^{2}\right)$, in the simplification rules (e.g., $\frac{a+b}{a}=b$ ), in the fraction rules (e.g., $\frac{a}{b}+\frac{c}{d}=\frac{a+c}{b+d}$ ). Besides, the factual errors (FE) in this study are mainly numerical computation errors or errors related to the incorrect use of formulas. For example, the error $3 x-$ $4 x=x$ is not an MEE error because the rule $a x+b x=$ $(a+b) x$ is applied correctly, but the error is in the numerical calculation of $3-4$ by replacing it with 1 instead of -1 . Another type of error that occurs in students' work is carelessness errors (CRE) when students are not careful and attentive. Table 1 provides a description and an example of each category.

\section{REVIEW OF STANDARD TEACHING METHODS}

In algebra courses, teachers use different approaches to teach students how to solve linear equations with one unknown. There exist three approaches that are currently most used. The first two approaches define the linear equation with one unknown as an equation where the variable has an exponent of 1 , and that can be written in the form $a x+b=0$ (where $a$ and $b$ are real numbers and $a \neq 0$ ). In order to solve these linear equations, the teacher asks their students to apply a sequence of steps for transforming equations until to get the unknown alone on one side (often the left-hand side) of the equal sign and everything else (constants) on the other. Both approaches involve the transformation of the original equation but in two different ways: one approach is based on the principle that if we add, subtract, multiply or divide an equation by the exact same constant or expression (except for 0 in multiplying and dividing ) to both sides, the two sides will remain equal. Thus, the students are requested to solve the equation by doing the same thing to both sides of the equation until the variable is isolated on one side. To explain what they should do, the teacher proposes several examples by progressing from simple equations of the form $x+a=b$ to $a x=b$ to $a x+b=c$ to $a x+b=c x+d$. For each equation, the teacher follows specific steps. For example, the third equation: $a x+b=c$ becomes $a x+b-b=c-b$ becomes $a x=c-b$ becomes $\frac{a x}{a}=\frac{c-b}{a}$ becomes $x=\frac{c-b}{a}$.

The other approach is based on the concept of inverse operations. The teacher often asks students to move the constants to the right side of the equation and the unknowns to the left, noting that by changing the side, the sign changes (wrong generalization). For example, for an equation $a x+b=c$, students first move $b$, it becomes $a x=c-b$ and then divide the right side by $a$ to isolate $x$ and find that $x=\frac{c-b}{a}$. For solving equations that contain parenthesis, the teacher explains the standard strategy organized as follow: (1) expanding the parentheses, (2) combining the unknowns and constants on each side, (3) transforming the unknown expression 
Table 2. Summary of the instructional sequence

\begin{tabular}{|c|c|}
\hline Lessons focus & Lesson goals \\
\hline $\begin{array}{l}\text { Equivalence of } \\
\text { algebraic } \\
\text { expressions }\end{array}$ & $\begin{array}{l}\text { Students should: } \\
\text { - Recognize the meaning of an algebraic expression as an object and formulate it. } \\
\text { - Recognize the meaning of the variable as a meaningless symbol in the calculation aspect and as a place } \\
\text { holder in the substitution aspect. } \\
\text { - Justify and identify the equivalence of algebraic expressions from a numerical view } \\
\text { - Justify and identify the equivalence of algebraic expressions from an algebraic view } \\
\text { - Identify the meaning of the equal sign ' }{ }^{\prime} \text { as expressing an equivalence relation between two algebraic } \\
\text { - Recognize the issue of restrictions on the equivalence of two algebraic expressions }\end{array}$ \\
\hline $\begin{array}{l}\text { Equivalence of } \\
\text { linear equations }\end{array}$ & $\begin{array}{l}\text { Students should: } \\
\text { - Perceive the equation as equality between two algebraic expressions. } \\
\text { - Identify the meaning of the equal sign ' }=^{\prime} \text { as a condition of equivalence. } \\
\text { - Identify the meaning of the variable as an unknown quantity. } \\
\text { - Realize that two linear equations are equivalent if and only if they have the same solution, and to use the } \\
\text { symbol " } \Leftrightarrow \text { " to express the equivalence between two equations. } \\
\text { - Understand the equality property of the sum: } A=B \Leftrightarrow A+C=B+C \text { knowing that } \mathrm{A}, \mathrm{B} \text { and } \mathrm{C} \text { are } \\
\text { algebraic expressions. } \\
\text { - Understand the equality property of the product: } A=B \Leftrightarrow A \times C=B \times C \text { knowing that } \mathrm{A}, \mathrm{B} \text { and } \mathrm{C} \text { are } \\
\text { - } \text { algebraic expressions and } C \neq 0 \text {. } \\
\text { - Find equations' solutions (if they exist) without solving them, but by looking for equivalent equations } \\
\text { - Fith known solutions. }\end{array}$ \\
\hline $\begin{array}{l}\text { Solving linear } \\
\text { equations using } \\
\text { the equivalence } \\
\text { approach }\end{array}$ & $\begin{array}{l}\text { The student should: } \\
\text { - Recognize equations that has an "immediate solution". } \\
\text { - Solve linear equations using the equivalence approach by following guidelines. } \\
\text { - Be able to determine and justify the steps used to solve an equation. } \\
\text { - Solve equations previously solved using a different ordering of transformations. } \\
\text { - Be able to solve equations using the equivalence approach after analyzing the given equation structure }\end{array}$ \\
\hline
\end{tabular}

to the left side and the constant to the right side of the equal sign, and (4) dividing the constant on the left side by the coefficient of the unknown (Star and Seifert,2006). The automatized procedures acquired from these approaches lead to a very superficial understanding of solving equations since these approaches focus on the technical use of the equal sign instead of on its meaning. Students do not understand the concepts behind the procedures; they are constrained while solving the equation by the steps that their teachers have indicated so they are less flexible. This lack of understanding might lead to increased difficulties with more complicated equations.

The third approach is the balance model that is an interactive and concrete tool to practice solving equations. While it makes the process easy to understand, it has physical limitations (e.g., negative signs and decimal coefficients) that may lead to cognitive difficulties.

\section{THE EQUIVALENCE APPROACH TEACHING METHOD}

The equivalence approach is based on two concepts: the equivalence of algebraic expressions and the equivalence of equations. Thus, students must first fully understand these concepts and then mobilize them to solve linear equations. With this perspective in mind, the teaching-learning goal was to develop an instructional sequence that would help students to understand the two concepts of equivalence and then use the equivalence approach to solve linear equations. It is believed that the instructional sequence, which required roughly twenty 60-min lessons, could be used with junior high school students who have already learned the operations of algebraic expressions. Therefore, students should be able to expand, factorize, and simplify algebraic expressions. These procedural skills are essential for the introduction of the concept of equivalence and its relation to the algebraic transformation of an expression. Table 2 shows an overall overview of the intended goals for this instructional sequence.

In the following paragraphs, the various tasks that are designed to achieve the objectives set out in Table 1 and explain students' mathematical activity when performing these tasks are presented.

\section{Equivalence of Algebraic Expressions}

First, the definition of algebraic expression is recalled, and it is noted that the arithmetic expressions can be considered as algebraic expressions with variables' coefficients equal to zero. To foster the meaning that algebraic expressions are objects (Kieran, 1992), and to guide students to reflect on the structure of the 
expressions, they were invited to identify the three components (variables, numbers, and operations) of some similar expressions (e.g., $2 x+3(x+1)$ and $(2 x+$ $3)(x+1))$. Thus, students should name the variables, the numbers, and the operations, specifying that the operation exists, for example, between the following number and the following expression. Secondly, activities to make students understand the concept of the equivalence of two algebraic expressions from a numerical and an algebraic view are proposed.

The first task was the numerical substitution of two algebraic expressions. It aimed for students to notice that the two expressions seem always to end with equal results when $x$ is replaced by the same value in each expression, and thus explains the notion of equivalence based on numerical equality. The task was followed by a question about the possibility of testing all values of $x$ to determine the equivalence. The no response motivated the search for a more general method to check the equivalence, which is the comparison of expressions using algebraic manipulations. Indeed, the second task was to ask students to simplify both expressions using expanding, factorizing, and simplifying techniques. This task aimed at developing the notion of equivalent expressions as expressions that can be written in a common algebraic form. For practicing, two exercises on equivalent algebraic expressions were proposed, where students were asked to:

- Select, from a list of algebraic expressions, the expressions that are equivalent to a given expression and justify their answers.

- Construct their own expressions that are equivalent to the two given expressions and justify their answers.

The next step was to draw attention to restrictions on equivalence. Two algebraic expressions are proposed that are equivalent on a set of admissible numbers. The two expressions were $2 x+1$ and $\frac{x(2 x+1)}{x}$. We asked the question "are these two expressions equivalent? ". Most students answer by yes, since $\frac{x(2 x+1)}{x}=2 x+1$. To generate a cognitive conflict, the numerical substitution of the two expressions was the next action. We aimed at students noticing that the two algebraic expressions gave the same value for all given values of $x$ except 1 . Indeed, it ensured that students understand that some expressions are equivalent only for a set of numbers different from the "prohibited values" called the set of admissible values. In contrast, how to determine this set was not a focus.

\section{The Meaning of Variable and Equal Sign}

The equivalence of two expressions $A$ and $B$ is expressed by the symbol of the equal sign ' $=$ ' (we write $A=B$ ), which develops a relational view of this symbol. According to many studies, there is a strong correlation between students' relational thinking of the equal sign and their abilities to understand the concept of equivalent equations (Knuth, Stephens, McNeil, \& Alibali, 2005). Different meanings of the equal sign and the variable used in this instructional sequence have been discussed, per the recommendations of many research projects. For example, Prediger (2010) has insisted on the importance of communicating explicit clarifications on the different meanings of variables and the equal sign. If not, the ambiguity of the students to their meanings can provide obstacles for understanding. We have adopted the five interpretations of the variable proposed by Malle (1993). In this sequence, the meanings of the variable are illustrated, as a placeholder in the substitution aspect, as a meaningless symbol in the calculation aspect, and later as an unknown in the situation aspect (equation). The equal sign was defined as a symbol of mathematical equivalence.

\section{Equivalence of Linear Equations}

After students have understood the concept of equivalent expressions, a new concept of equivalence of the equation was introduced.

\section{Equation definition}

The first objective was to link an equation and algebraic expressions. The equation was defined as equality between two algebraic expressions (equation $A$ $=B$ ), at least one of which contains a variable. That the variable is interpreted as unknowns, and that the equal sign represents an 'equivalence condition' of the two expressions $A$ and $B$, verified for specific values of the unknown called solutions, is emphasized. 'Solve the equation $A=B^{\prime}$ is a question about the values of the unknown $x$ that will verify the equivalence of the algebraic expressions $A$ and $B$.

\section{Equivalent Equations}

It was explained to students that linear equations are equivalent if they have the same solutions, where their equivalence is expressed by the symbol $\Leftrightarrow$. An example was given: $x+1=3$ is equivalent to $2=4-x$, since they have the same solution 2 and ' $x+1=3 \Leftrightarrow 2=4-x^{\prime}$ is written. To avoid students' misconceptions about the concept of equivalence, they were warned not to confuse the equivalent expressions and the equivalent equations, and they were given examples.

\section{Equality properties}

The next step was to explain the equality properties as tools for identifying or constructing equivalents equations. The first property says that the equation $A=$ $B$ is equivalent to the equation $A+C=B+C$. The second property says that the equation $A=B$ is equivalent to the equation $A \times C=B \times C$ and $C \neq 0$, knowing that $A$ and $B$ are the equation's expressions in parenthesis and $C$ is 
any algebraic expression defined on the set of real numbers in parenthesis. These properties mean that "if you do the same operation to both sides of an equation, it remains the same". But the authors of this paper believe that this way of presentation (e.g., $A=B \Leftrightarrow A+C$ $=B+C$ such that $A, B$, and $C$ are algebraic expressions) is mathematically more accurate and helps students to better understand and avoid errors in the transformation of equations.

In this part of the course, three activities are proposed. The students were given seven equations using the first property and were asked to judge which of these equations are or are not equivalent to the equation $7 x+3=2 x-5$. They were also given eight equations using the second property and were asked to judge which of these equations are or are not equivalent to the equation $10=x+2$. The next task asked students to link each equation in list 1 to its equivalent equation in list 2, where the transformation made on the equivalent equations use both equality properties. The students were asked to write explanations of how they arrived at their decisions. It was noticed that most of the students were trying to solve the equations to check the equivalence, which is why they were asked to answer without solving the equations, as it was desired that they recognize the equivalence of two equations according to their structure through the use of the equality properties. In another task, students were asked to propose two equivalent equations of the equation $3(x-1)+8=x+1$ which are written as the form: $a x+b=0$ and $x+c=d$ such that $a, b, c$, and $d$ are real nonzero numbers. This task has facilitated the introduction of the equivalence approach for solving linear equations that is described in the following paragraphs.

\section{Solving Linear Equations Using the Equivalence Approach}

First, it was explained to students that the action that consists of looking for the value of $x$ and verifies the equivalence of the algebraic expressions $A$ and $B$ is called: 'solving the equation $A=B$ '. For solving the equation $A=B$ an approach based on the concept of equivalence will be used: the equivalence of algebraic expressions and the equivalence of equations. In the second step, students were asked about examples of equations that are immediately solved, in other words, equations with easy-to-deduce solutions. They were also asked to give the general forms of these equations. In return, students proposed the equations of the form $x+$ $c=0, a x=0, x=a$, and $x+c=d$ such that $a, b, c$ and $d$ are integers.

The principle of the equivalence approach was then explained by saying that: to solve any linear equation, one should seek successive equivalent equations of the equation in question until arriving at an equivalent equation of an immediate solution. This is achieved (a) by applying the equality properties or (b) by replacing the algebraic expressions of the two sides (the left side or the right side or both at the same time) of the equation by their equivalent expressions. This explanation was followed by a series of problem-solving tasks, through which students applied the equivalence approach to solving linear equations but in different contexts. An example of each task is presented hereafter.

In the activity shown in Figure 1, students were asked to solve three linear equations by following guidelines, either by applying an equality property (sum or product) or by replacing the algebraic expression with an equivalent one. Our goals were (a) to get students accustomed to looking for an equivalent equation at each stage of the solving process using the transformation steps in different ways and (b) help them to be aware of each step and the original procedure behind it. To get students focused on the solving steps, they were given the last equivalent equation $x=11$ with an immediate solution 11. Their challenge was to choose the appropriate expression $C$ when applying the indicated properties. This activity is similar to the one proposed by Star and Seifert (2006), which consists of asking students to solve previously completed equations using a different ordering of transformations. As a result, they find that the alternative ordering tasks were powerful in helping students to be more flexible solvers.

The purpose of the activity in Figure 2 was to help students to be aware of their actions in solving the equation and to be able to interpret each transformation as an application of either property of equality (sum or product) or replacement of an expression by an equivalent one. Therefore, when the student would be faced with an equation of an unfamiliar structure, the student would be "programmed" that no transformation would be done unless it is one of these three actions. Their solving strategy was additionally guided by adding the expression $-\frac{x+2}{3}$ in the first step, an action that is not obvious to students since it is different from the standard solving strategy. The objective is to show the students that it is necessary to choose the suitable expression $C$ to add or to multiply to solve the equation in the least possible steps.

In the last activity, students were given ample freedom to use their own strategies. we asked them to use the strategy which they considered the best. During the discussion of the solution strategies, students were asked to explain why they had chosen the strategy and to justify each transformation step. It is noteworthy to mention that giving the students isomorphic equations overly practiced with particular methods in all the previous activities was avoided to prevent their gaining fluency with only one particular solution strategy. The students were induced to think about the appropriate solution strategy according to the structure of the equation and the three acquired tools. Some studies have confirmed that if the students were "used to" practicing 
1. Propose three strategies for solving the linear equation $3(x+1)=36$ to arrive at the equivalent equation $x=11$ by considering the guidelines presented for each step.
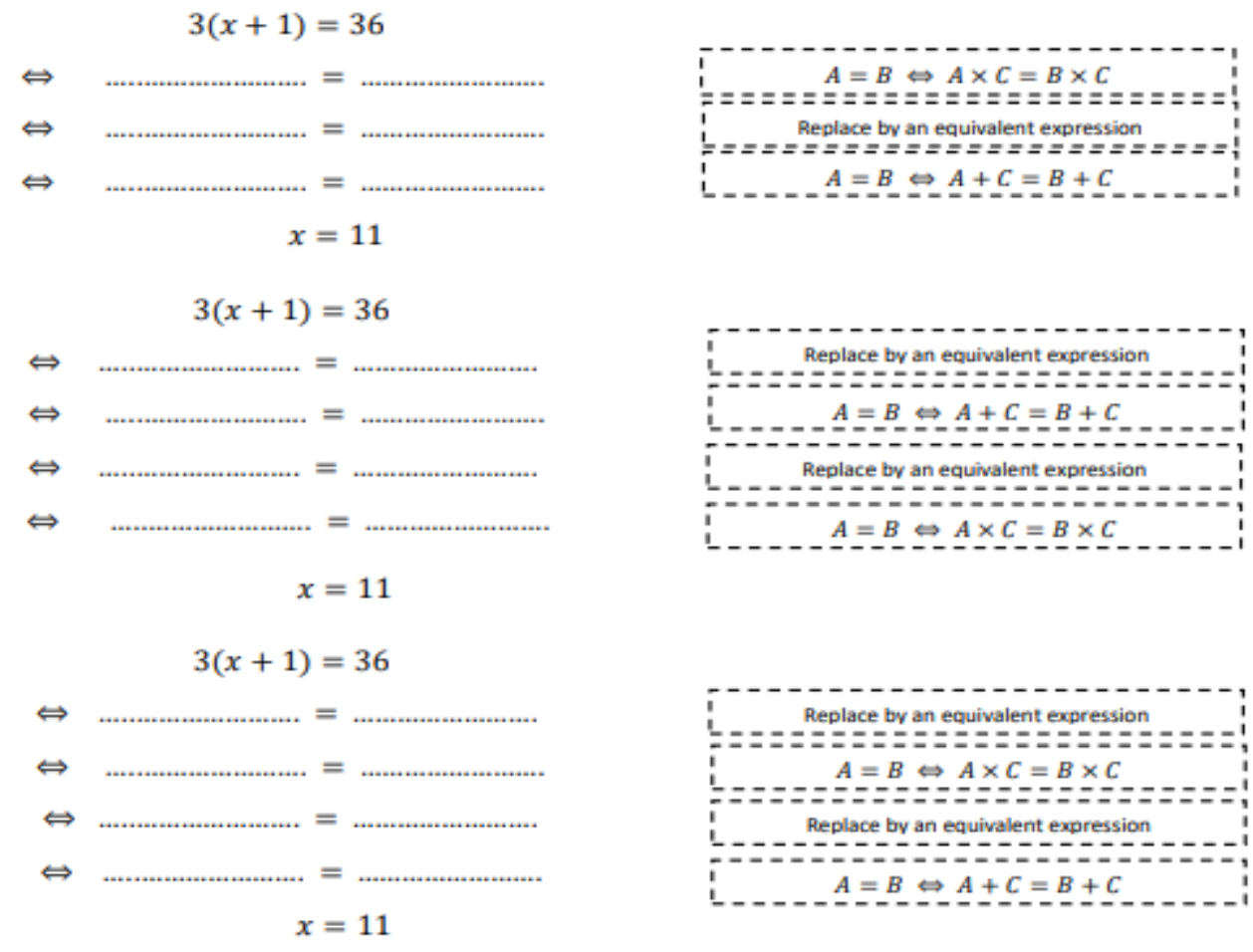

2. Which of the three strategies is the best for you and why?

Figure 1. The first activity on solving a linear equation by different strategies following guidelines

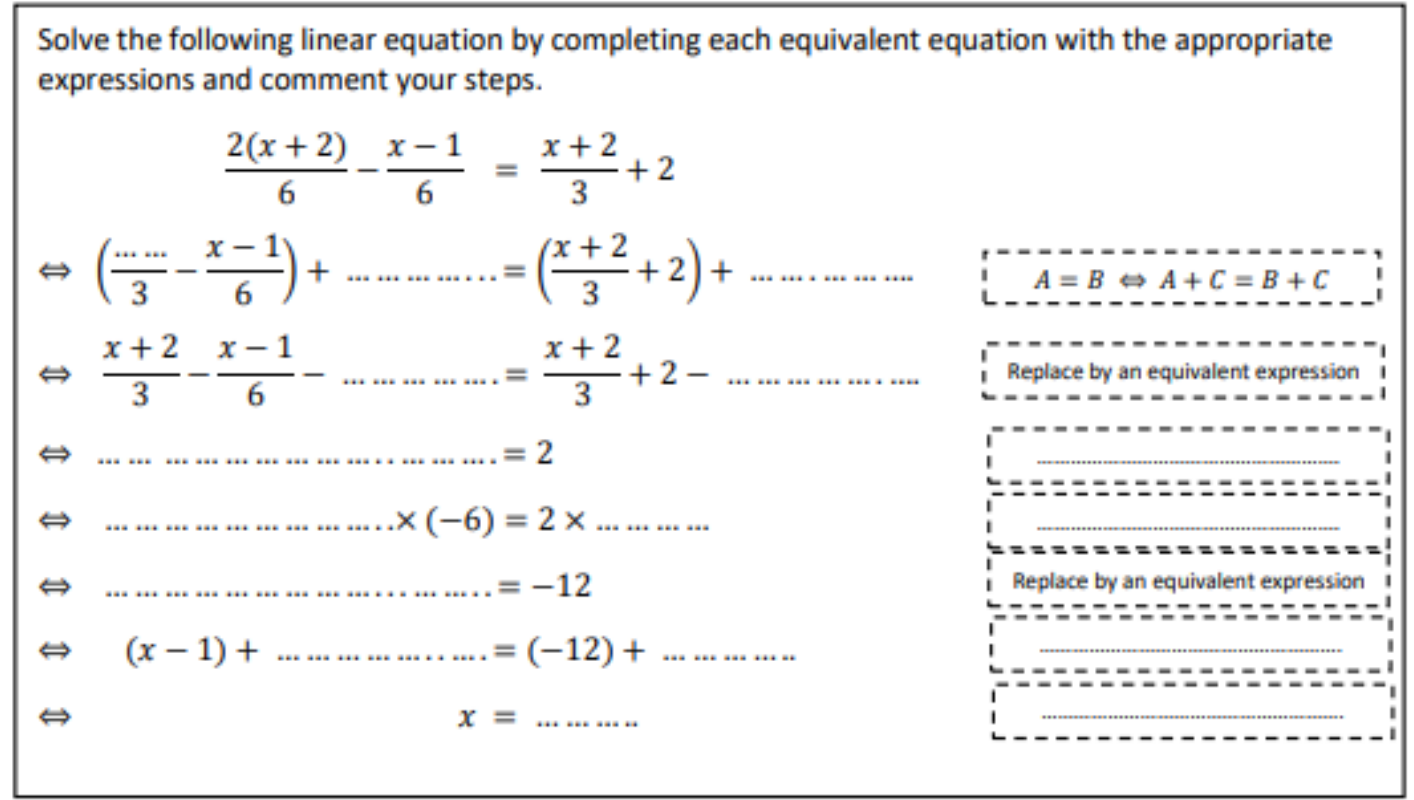

Figure 2. The second task on solving linear equation by completing each equivalent equation with the appropriate expressions and commenting on some steps

a specific solution strategy, they will not necessarily use alternate methods although they have acquired knowledge of said alternate methods (Blöte et al., 2001; Star \& Rittle-Johnson, 2008).

\section{METHODS}

\section{Research Design}

The focus of this study was to know if the equivalence approach teaching method that enhances the students' 
conceptual knowledge can impact their procedural knowledge in terms of flexibility, optimality, and prevent errors in solving linear equations. To answer the research questions, the first step was to identify the students' prior knowledge and their performance in solving algebra problems, and so the suitable sample for the study was selected by assigning randomly the participants to two groups (experimental group and control group). The second step consisted of implementing the two teaching methods, the traditional one for the control group and the EA for the experimental group. The last step involved testing the effectiveness of the teaching methods on participants' performance in solving unfamiliar problems about linear equations resolution. The study adopted the posttestonly control group design. This research design was considered suitable because the researchers aimed to find out how the students of both groups were going to behave in front of tasks not already seen, to which they were unaccustomed, and more complex than previously experienced (which was not possible in Pre-Post-test research design). The researchers, therefore, aimed at verifying if the conceptual knowledge taught to the experimental group (EG) students was going to favor them in performing these tasks correctly better than the control group (CG) students.

\section{Participants}

The study was conducted in a public high-school in Casablanca, Morocco. The students in this school come from families with similar socioeconomic statuses. The target population of this study comprised of junior high school students, who were generally around $15-16$ years old. At the beginning of the school year, diagnostic-tests are proposed to students to determine their school-level and their prior knowledge in the areas of algebra, geometry, and trigonometry. The algebra test contains tasks on the algebraic calculation (expressions expansion, expressions factorization, simplifying fractions, square roots, and exponents), and tasks on solving linear equations. Therefore, the algebra test allowed us to classify the students in three levels; students who have high, medium, and low Algebra skills. The participants in our study are all from the higher-medium students of three classes, that are assigned randomly to two groups: experimental group (EG) and control group (CG). The low achieving students were not selected because they did not have the essential prerequisites which would allow correctly judging the effects of our intervention.

To match the EG and the CG as far as possible, random assignment of 61 participants to both groups was made by level and gender as follows: 11 highachieving girls were randomly assigned to the two groups, likewise for 14 high-achieving boys, 16 mediumachieving girls, and 20 medium-achieving boys. The EA teaching method was administered only to the EG, whereas the CG was taught using the traditional teaching method. For the control group, the teacher showed the different operations on the expressions and then the techniques of solving linear equations ("doing the same thing to two sides except for multiplying by zero" or "moving numbers to another side") following the usual working method. The teacher noticed that most CG students are more likely to move the numbers to the other side instead of adding the same term to both sides. For the experimental group, the teacher started with explaining the equivalent algebraic expressions, then the equivalent equations, and finally the equivalence approach strategy for solving linear equations.

The researchers trained the teacher on the EA teaching method. To prevent overlap between the two teaching methods, and at the same time getting both groups of students learning process in parallel, the training sessions were scheduled over two periods. The first one was devoted to training the teacher on how to teach the algebraic expressions using the EA after he has previously taught the CG the same topic using his traditional method. Similarly, the second training session was about teaching linear equations using the EA after the teacher has already taught the CG students solving linear equations using the traditional methods. The last week was devoted to doing exercises that allowed participants of both groups to practice solving linear equations, noting that the equations proposed in these exercises are the same for both groups. A member of the research team was always present during both group sessions.

\section{Data Collection}

The data were collected from students' responses to the posttest at the end of the treatment. The teacher administered the posttest to both the experimental group and the control group as a written assessment in two different and successive sessions. The assessment included two tasks that measured students' procedural knowledge of solving equations process. Students were given two hours to complete the assessment.

\section{Task 1: Measure of flexibility}

The first purpose of the current study was to investigate the impact of the equivalence approach compared to the standard teaching strategy on students' flexibility in solving linear equations, which is to test hypothesis 1. For this purpose and based on prior research the participants' ability to solve linear equations using multiple strategies, to invent new solution procedures, and to select the most appropriate and efficient strategies were examined. Specifically, at the posttest four equations (see Table 3) were proposed, where each was designed with a feature and could be solved using atypical and efficient strategies or using 
Table 3. Equations of Task 1 of the Posttest

\begin{tabular}{ll}
\hline 1 & Equations \\
2 & $(14 x-21)-2(2 x-3)=4(2 x-3)$ \\
3 & $\frac{1}{2}\left(2(x+1)^{2}+3 x\right)=x^{2}+2 x+1-\frac{5}{2} x$ \\
4 & $\frac{x}{3}+\frac{10}{9}=-\frac{2 x}{3}-\frac{8}{9}$ \\
\hline
\end{tabular}

Table 4. Equations of Task 2 of the posttest

\begin{tabular}{ll}
\hline 1 & Equations \\
2 & $\frac{x^{2}-9}{x+3}=0$ \\
3 & $\frac{4}{x^{2}+x}=-\frac{1}{x+1}$ \\
\hline
\end{tabular}

standard strategy. However, atypical strategies refer to the strategies that involve a certain kind of invention in the transformation steps of a given equation, and efficient strategies refer to the strategies that require the fewest number of steps and/or the least computations to execute (See the section on Data Analysis for more details).

\section{Task 2: Measure the errors' frequency}

To answer our research questions and test its equivalent hypothesis Task 2 was designed to test students' ability to solve three unfamiliar equations (see Table 4). Indeed, the participants of both groups had an opportunity to work on rational equations with fractions on one side or two sides of the equal sign. The two equations proposed in task 2 are rational equations that additionally contain variables in the denominator and that are reduced to linear equations. The last equation is a third-degree equation which can also be reduced to a product of linear equations. It is noted that all participants understood that if $A \times B=0$ so $A=0$ or $B=$ 0 and learned how to solve quadratic equations using the quadratic formula. For a more detailed explanation of the tasks, refer to the findings section. Instructions were given by the teacher as follows: you will not need any new knowledge to solve these equations. All you have learned over these last weeks is enough, so benefit from them. Please do not skip any step of the chosen solving strategy, give detailed answers.

\section{Data Analysis}

In this section detailed coding of the participants' responses to each assessment task is provided. To check the inter-rater reliability a high school mathematics teacher -not included in this study- was invited to be a second coder after an explanation of the coding rubric by the authors. Cohen's kappa statistic was used to measure inter-rater reliability. Due to the nonnormal distribution data, the Mann-Whitney U Nonparametric Test was used, after testing the assumptions, to compare differences in posttest scores between the two independent groups. To determine the significance of the results the obtained $\mathrm{p}$-values were compared to 0.05 .
All statistical analyses were conducted using IBM SPSS statistics 25 software.

\section{Task 1: Measure of flexibility}

To answer the research questions, the participants' ability (a) to solve four equations using multiple strategies and (b) to invent new solution procedures more efficient and/or that required less effort and fewer computations, was assessed. For this purpose two variables were created. The first variable indicated the total number of strategies used to solve the four equations for each participant. For example, if the number of strategies selected by the coders for a participant is 2 for the first equation, 3 for the second, one for the third, and 2 for the fourth, then the total number of strategies assigned to that student is 8 strategies. It should be noted that for a strategy to be considered as such (to be counted), it must differ from the other strategies used to resolve the same equation in the order of the transformation steps. For example, for equation $1,(14 x-21)-2(2 x-3)=4(2 x-3)$, a student in the experimental group used two solution strategies: the first consisted of EXPANDING $(10 x-15=8 x-12)$, ADDING the expression $-8 x+15$ to both side $(10 x-8 x$ $=-12+15)$, COMBINING $(2 x=3)$, and MULTIPLYING by $\left.\frac{1}{2}\left(x=\frac{3}{2}\right)\right)$; the second consisted of EXPANDING $(10 x-15=8 x-12)$, ADDING the expression $-8 x+12$ to both side $(10 x-15-8 x+12=0)$, COMBINING $(2 x-3$ $=0)$, ADDING the expression 3 to both sides $(2 x=3)$, and MULTIPLYING by $\frac{1}{2}\left(x=\frac{3}{2}\right)$. These two strategies are considered identical because the student thought in the same way for both strategies, using the same standard order of transformations.

The second variable indicated the total number of times the student invented an atypical procedure deemed by the coders to be easy and appropriate to the equation features- to solve one of the four equations. For example, if a student used an invented strategy 5 times, then they would receive a score of 5 for the invention variable. In this study, an invented strategy is a strategy that involves the use of transformations in optimal ways. For example, COMBINE a changed variable (e.g., 
Table 5. Results on the use of multiple solution strategies

\begin{tabular}{|c|c|c|c|c|c|}
\hline Groups & $N$ & Mean Rank & Mann Withney U & P-value & Significance \\
\hline$C G$ & 31 & 23.08 & 219.5 & .000 & Reject null hypothesis \\
\hline$E G$ & 30 & 39.18 & & & 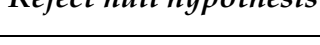 \\
\hline
\end{tabular}

transforming $7(2 x-3)-2(2 x-3)=4(2 x-3)$ to get $5(2 x-$ $3)=4(2 x-3))$, CANCEL repeated expressions from both sides (e.g., transforming the equation $\frac{1}{2}\left(2(x+1)^{2}+\right.$ $3 x)=x^{2}+2 x+1-\frac{5}{2} x$ to get $\left.\frac{3}{2} x=-\frac{5}{2} x\right)($ Star, 2006). In addition, invented strategies also involve strategies that are not necessarily optimal (contain more steps) but require less effort since they make the equation easier to solve. For example, multiply the entire equation $2 \sqrt{3} x+$ $\sqrt{12}=\sqrt{3} x-\sqrt{3}$ by the constant $\sqrt{3}$ to render all the coefficients of unknowns and the constants entire numbers $6 x+6=3 x-3$, so that the calculations can be done easily and with fewer errors.

Interrater reliability using Cohen's Kappa value was 0.87 for the first variable and 0.9 for the second variable; the disagreements were discussed and solved by the coders. The Mann-Whitney U test was used to measure the differences between the two independent groups (EG and CG), where the considered variables are the number total of strategies and the number of inventions used to solve the four equations.

\section{Task 2: Measure the errors' frequency}

To answer the research questions about the contribution of the equivalence approach in minimizing students' error patterns, the students' responses to Task 2 were coded according to the frequency of errors committed for each category. The development of the coding rubric was based on existing research regarding errors' categorization (See Literature Review section). Therefore, students' errors were classified into one of the following six categories: conceptual errors (CE), transformation errors (TE), expressions manipulation errors (MEE), factual errors (FE), carelessness errors (CRE), and other. For each student, the research team looked for all errors made by the student in solving the three equations of Task 2 and then assigned each error to the appropriate category. Finally, the number of errors made by each student in each category was counted and saved in a file (e.g., Participant 1 made 2 CE, 1 TE, 0MEE, 1 CSE). With Cohen's Kappa value of 0.94 on average, the agreement between coders was almost perfect. The Mann-Whitney $U$ test was used to compare the differences between the two independent groups (EG and $(G)$, where the considered dependent variables are the errors' score for each category.

\section{RESULTS \& DISCUSSIONS}

This section is organized around two research questions: a) the impact of the equivalence approach in students' flexibility (the use of multiple solution strategies and select "invented" strategies), and b) its effect in minimizing students' errors in solving equations. Overall, the results indicated that the equivalence approach improved flexibility and minimized errors committed to solving the equations. To this end, the statistical findings will be presented and students' written works will be analyzed.

\section{Measure of Flexibility}

\section{Using multiple strategies for solving equations}

The results in Table 5 indicate that there was a significant difference in EG performance using multiple solution strategies compared to CG performance. As hypothesized, the equivalence approach to solving linear equations worked significantly better than the standard teaching method in developing students' ability to diversify solving steps. It is believed that this result is self-evident because the equivalence approach does not focus on teaching procedural rules for solving equations and using repetition to foster the memorization of these rules as the standard method does. It, instead, explains the structure of the equation as equality between two algebraic expressions and presents the process of solving an equation as a search for an equivalent equation of immediate solution, and then leaves the students a degree of freedom to use the transformation tools (property of equality of the sum, property of equality of product, replace by an equivalent expression), without strategic instructions on how transformations could be used, to find this equation. Therefore, this supports independence and self-reliance among students in the choice of the solution steps using expressions defined on the set of real numbers.

To get a closer view of these results, some strategies used for each group (EG and CG) are presented. It was found that $77 \%$ of the control group used either a single strategy or two to three strategies that were, in fact, the same. Thus, these strategies are composed of the same order of transformations, the difference exists in the application of this transformation, especially the first transformation. For example, some participants moved the unknowns to the left side and the constants to the right side in the first strategy, and in the second strategy they moved all the unknowns and constants to the left side in the first step, combined them, and then moved the constant back to the right side; others transformed the equation $A=B$ into the equation $-B=-A$ and then used the standard method to solve it. As another example of "same strategies", in equation 3 some participants convert the equation to a common denominator of 9 in strategy 1 and to a common denominator of 18 in strategy 2, and then in both 


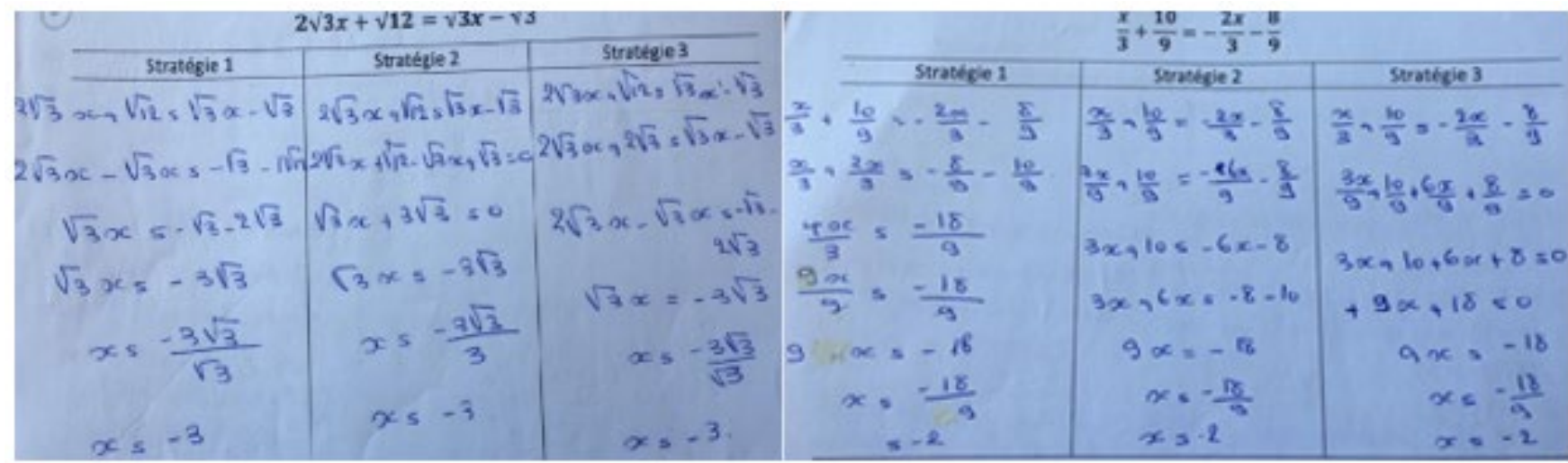

Figure 3. Example of CG students' written work

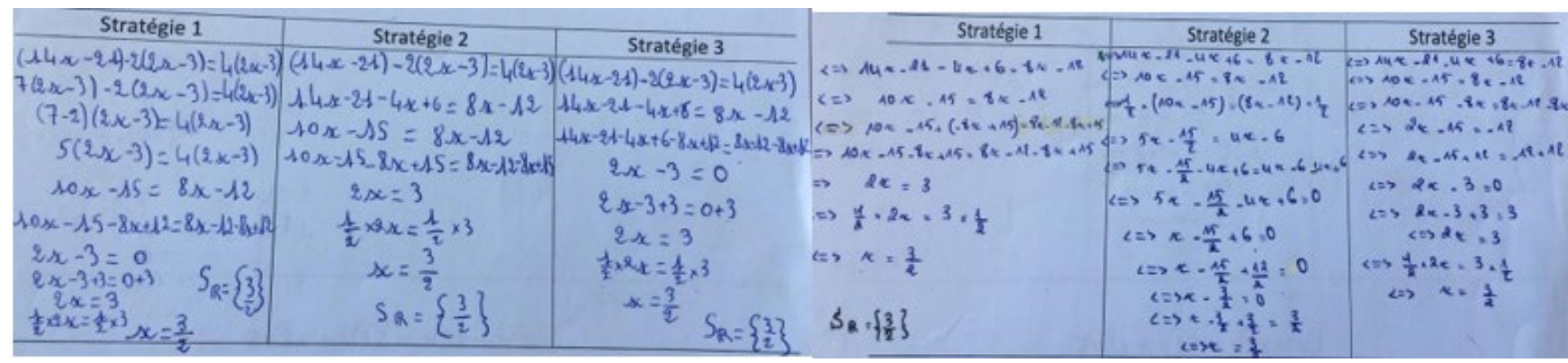

Figure 4. Example of EG students' written work

Table 6. Results on the use of invented solution strategies

\begin{tabular}{lccccc}
\hline Groups & $N$ & Mean Rank & Mann Withney $U$ & P-value & Significance \\
\hline CG & 31 & $\mathbf{2 2 . 1 1}$ & 189.5 & $\mathbf{. 0 0 0}$ & Reject null hypothesis \\
\hline EG & 30 & $\mathbf{4 0 . 1 8}$ & $\mathbf{1 8 9 . 5}$ & &
\end{tabular}

strategies they eliminate the denominators and equate the numerators, and then continue with the standard method to find the solution. Figure 3 includes examples from control group students' written work.

For the experimental group it was noticed the same phenomenon of "same strategies" was present, but with a smaller percentage of $36 \%$, which reveals some students' resistance to change, since they considered the standard method easier and safer. They solved the equation with the traditional method using the equivalence approach. For example, in equation 1, after they expand and combine the expressions to obtain the equation $12 x-5=11 x+3$, they add to two sides the expression $C=-11 x+5$ in strategy 1 and the expression $C=-11 x-3$ in strategy 2 . Moreover, it was noted that $20 \%$ of EG participants solved the equations using strategies that contain additional steps and complicate the solution strategy, even if they respect the concept of equivalence. For example, in equation 1 , they multiply in the first step by $\frac{1}{2}$ or $\frac{1}{7}$. See Figure 4 for more examples. We justify the use of these strategies by the fact that the instruction of task 1 asks the students to solve the four equations using three different strategies without requiring these strategies to be optimal.

However, frequencies of participants who used multiple appropriate strategies was $43 \%$ for the experimental group and $22 \%$ for the control group.

\section{Using "Invented" strategies for solving equations}

The results from Table 6 show that students who received the equivalence approach intervention were significantly better able to solve equations using invented strategies at posttest than students who received the standard teaching method. We found that $22 \%$ of the control group used at least one invented strategy in solving the four equations, compared to $53 \%$ of the experimental group. Examples of invented strategies are presented in Figure 5.

We believe that these results are justified, since some of the advantages of the equivalence approach teaching module over the traditional teaching module are: in the traditional method the structure of the equations is not discussed, the procedural steps for solving equations are not justified, and the concepts underlying these operations are not explained; however, in the EA teaching module, the structure of the equations are first stressed, the procedural steps for solving equations are presented as tools for searching for an equivalent equation of immediate solution, and the concept of equivalence is discussed in each transformation step. Therefore, the student, in the traditional teaching module, is unable to justify his thinking and more likely to be attached to particular strategies or bound to a certain fixed order of transformation, and even if 


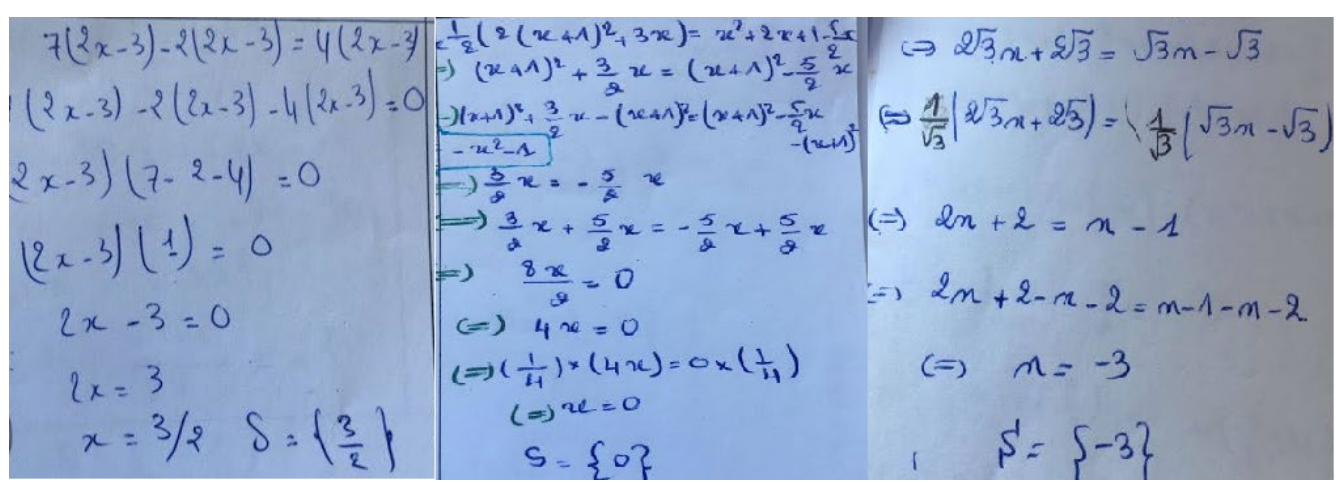

Figure 5. Example of invented strategies

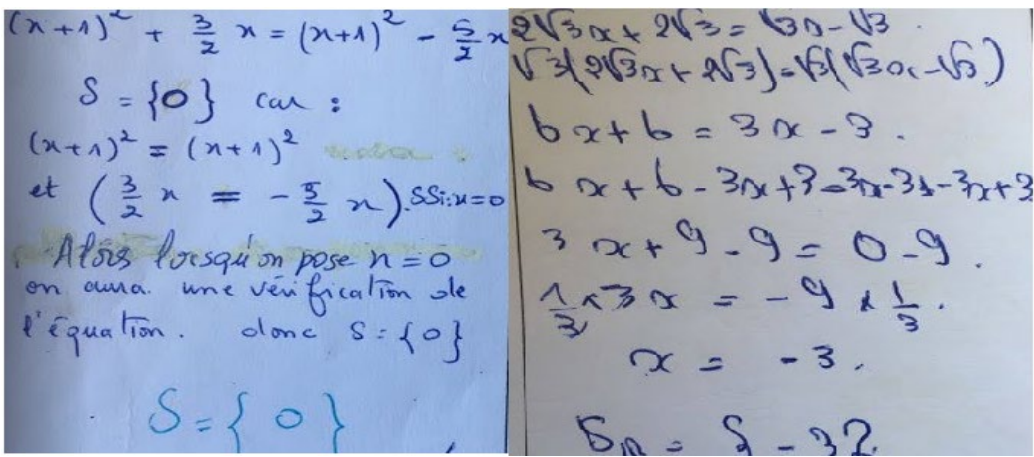

Figure 6. Invented strategies of EG students

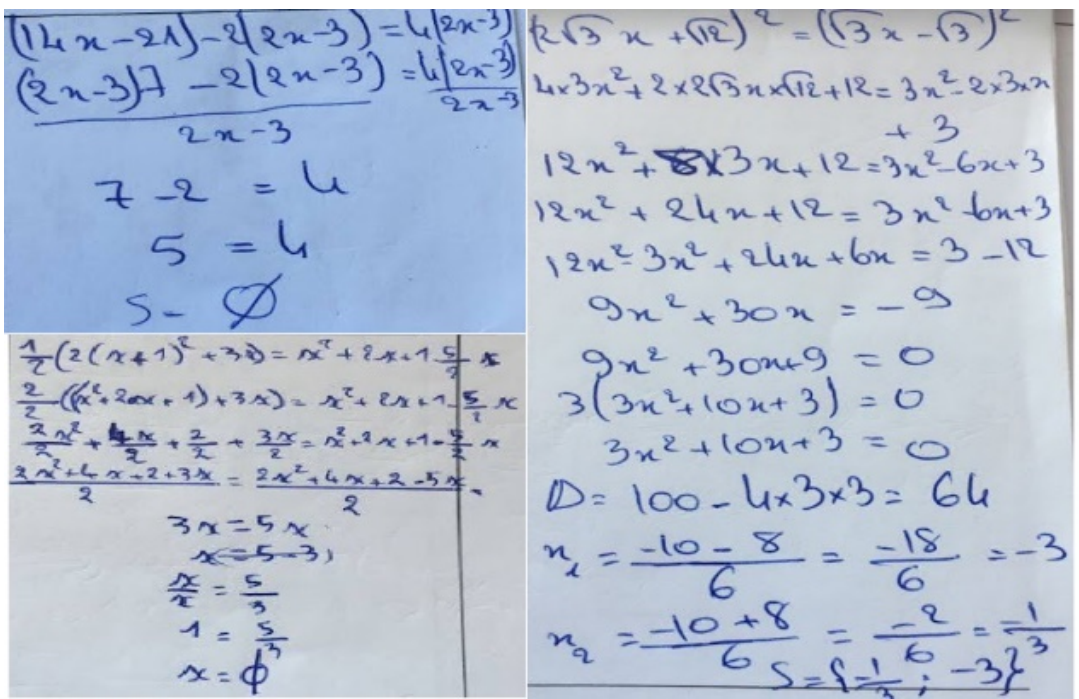

Figure 7. Incorrect solution strategies used by CG students

alternate methods are known they will not tend to be used because the student is "used to" employing a particular method (Star \& Rittle-Johnson, 2008). The student in the EA teaching module is more flexible because they did not receive direct instructions about a specific order of transformations to use for solving equations, or were not be overly exposed to solving repeated equations. Instead, they learned a set of tools, and the teacher had the role of explaining why and how they could be applied.

Some inventions were particular (See Figure 6), for example, when participants deduced the solution directly from the structure of the equation (e.g., since
$5(2 x-3)=4(2 x-3)$ then the solution is $\left.\frac{3}{2}\right)$. Another example of a particular invention was to multiply the entire equation 4 by $\sqrt{3}$ to have integers coefficients and constants. Thus, $16 \%$ of the experimental group participants used particular invented strategies, whereas none of the control group participants did so.

Some inventions have been considered incorrect and show a lack of understanding of the concept of equivalence (see Figure 7). For example, squaring the two sides of the 4 th equation, dividing by $(2 x-3)$ in the first equation. These types of strategies were used by $16 \%$ of the control group and none of the experimental group. 
Table 7. P-value of each error category

\begin{tabular}{lccccc}
\hline Category of errors & $C E$ & $T E$ & $M E E$ & $F E$ & $C S E$ \\
\hline P-value & $\mathbf{0 . 0 0 0}$ & $\mathbf{0 . 0 0 2}$ & $\mathbf{0 . 4 7 3}$ & $\mathbf{0 . 4 5 2}$ & $\mathbf{0 . 6 5 0}$ \\
\hline
\end{tabular}

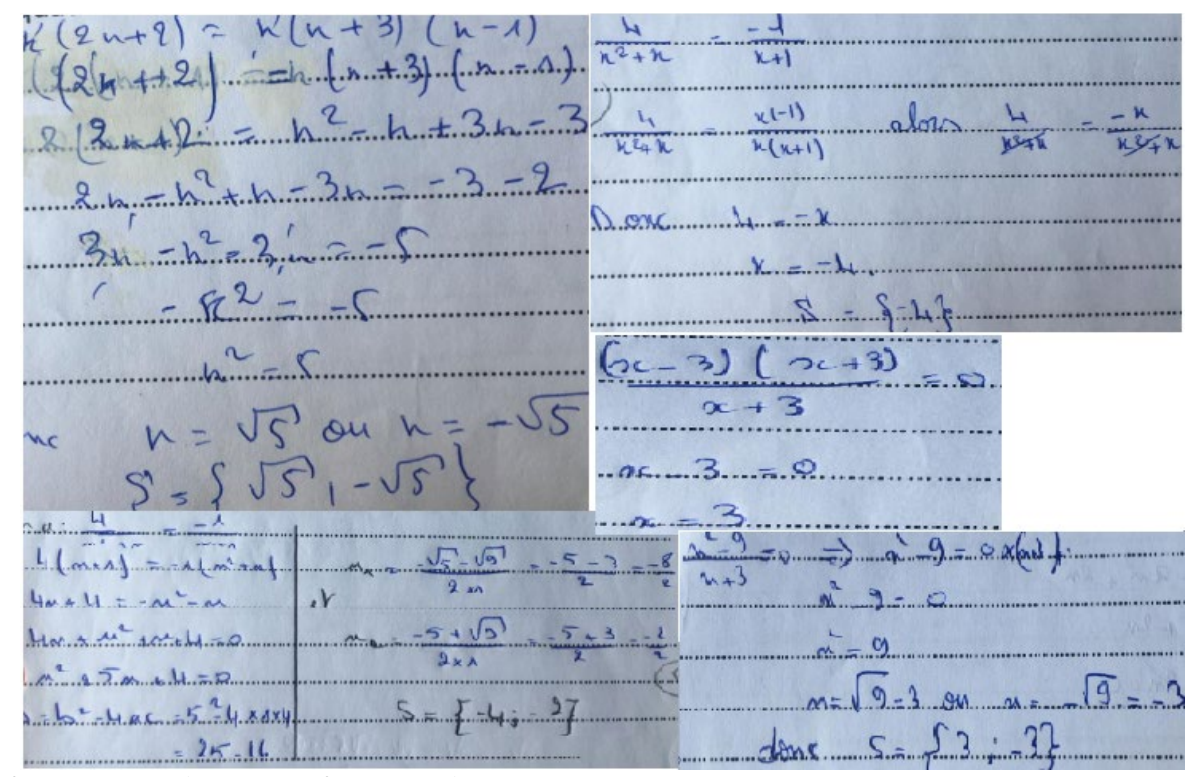

Figure 8. Example of Conceptual Errors of CG students

According to these findings our first hypothesis is affirmed, that the equivalence approach improves the flexibility of the students in solving equations. These results are consistent with results from prior studies previously presented. In the approach of this paper, conceptual and procedural knowledge of equations were combined by, on the one hand, explaining the concept of equivalence of expressions and equations, and on the other hand by teaching procedural knowledge in a way that leads to flexibility, which allowed students to be flexible solvers with deep knowledge of the equation concept (Baroody \& Dowker, 2003; Broody, Feil, \& Johnson, 2007; Hiebert \& Carpenter, 1992; NCTM, 2001; Rittle-Johnson \& Star, 2007; Star \& Seifert, 2006).

\section{Measure the errors' frequencies}

The results from Table 7 indicate that errors in manipulating expressions (MEE), factual errors (FE), and carelessness errors (CSE) were committed in an almost similar way by the participants of both groups; however, the results for conceptual errors and transformation errors pointed to a significant difference in the number of these errors committed by each group in favor of CG.

It is believed that the results of the MEE, FE, and CSE category errors are due to the following reasons: on the one hand the total errors of each category do not exceed 18 errors on the four equations for the two groups while on the other hand, for both groups and taking into account the time constraint, neither the algebraic calculation (expanding, factorization, calculation on fractions, on square roots, and on exponents) nor the arithmetic calculation were focused on. For this reason students of higher-medium level in these types of calculations were selected.

For conceptual errors about $93 \%$ of CG students used strategies where they canceled the denominators (e.g., $\frac{x^{2}-9}{x+3}=0$ becomes $\left.x^{2}-9=0\right)$, used the crossmultiplying rule (e.g., $\frac{4}{x^{2}+x}=-\frac{1}{x+1}$ becomes $4(x+1)=$ $\left.-1\left(x^{2}+x\right)\right)$, or/and simplified by a product expression on each side of the equation (e.g., $x(2 x+2)=x(x+$ $3)(x-1)$ becomes $(2 x+2)=(x+3)(x-1))$, without taking into account the "prohibited values" that the unknown $x$ can take. Finally, they found "prohibited solutions" or they lost solutions (see Figure 8 for examples).

However, $36 \%$ of the EG students made this type of error. The rest set conditions on $x$ to ensure equivalence between equations, since they knew that if the equivalence conditions are not respected in each transformation step then the solution strategy will be wrong (see Figure 9).

For transformation errors, it was found that $29 \%$ of the CG students made errors in moving the expressions from one side to the other side of the equal sign, for example, transforming equation $\frac{x^{2}-9}{x+3}=0$ into $x^{2}-9=$ $x+3$ and then into $x^{2}-9-x-3=0$ (see Figure 10 for more examples). However, no person from the experimental group made a transformation error. This is explained by the fact that most students from the control group preferred to solve the equations by moving the expressions from one side to the other of the equal sign, and in these moving operations they fell into transformation errors, whereas the EG students learned 


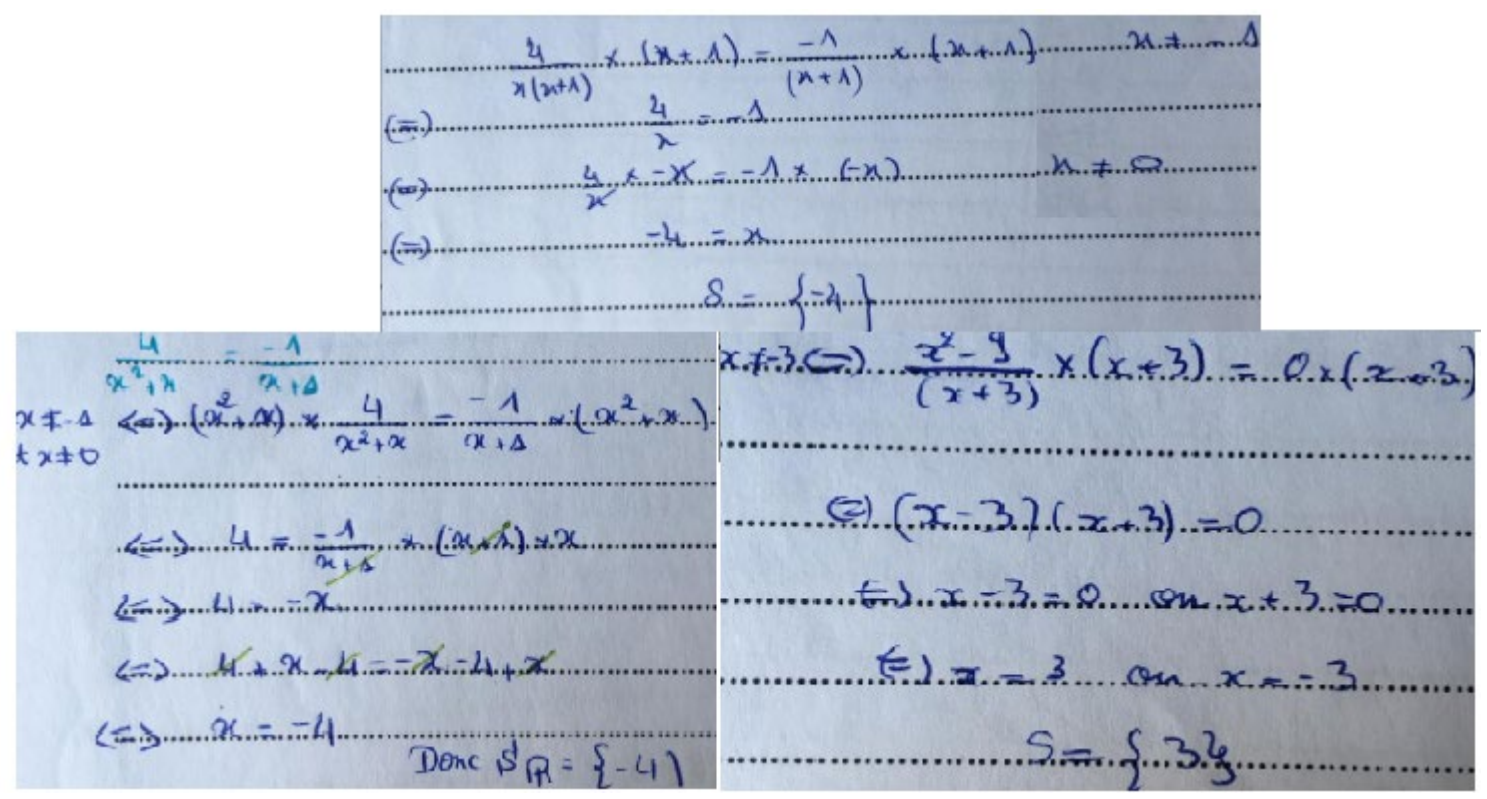

Figure 9. EG students' written work of Task2

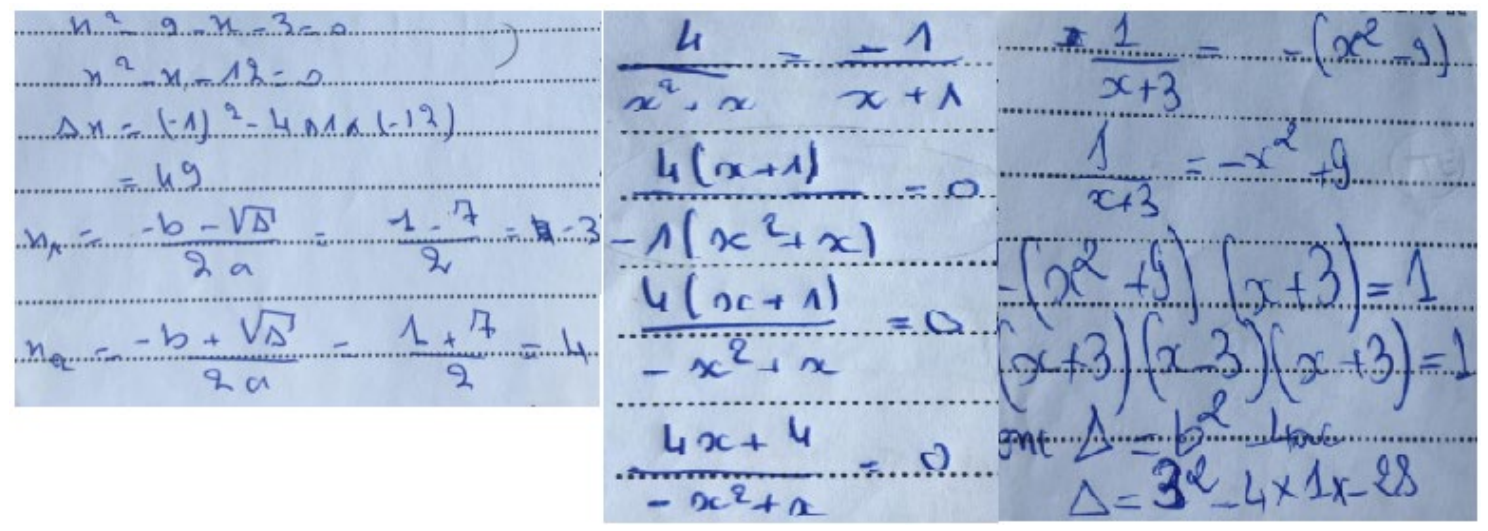

Figure 10. Example of Transformation Errors

the EA method for solving equations using the equality properties in their "original" form $(A=B$ equivalent to $A+C=B+C$ or $A=B$ equivalent $A \times C=B \times C$ and $C \neq 0$ ), such that $A$ and $B$ are the equation's expressions in parenthesis and $C$ is any algebraic expression defined on the set of real numbers in parenthesis.

In summary, the EA teaching module emphasizes conceptual understanding and presents solid and always accurate procedural knowledge, which contributes to the minimization of two types of errors: conceptual errors and transformation errors.

\section{CONCLUSION}

Students' misunderstanding of the equivalence concept has been confirmed by many studies, and many researchers have emphasized the need to teach this concept explicitly to improve students' conceptual and procedural knowledge about equations (Steinberg, Sleeman, \& Ktorza, 1990). Others insisted that the algebraic expressions of the equation should be presented as objects and that the different meanings of variables should be clarified (Prediger, 2010). Moreover, some researchers found that most students' errors, and their lack of flexibility in solving equations, are related to misconceptions about these concepts. Others believed that these are related to procedural knowledge being taught in a way that focuses on the rote execution of memorized algorithms. In this study all this research was considered to propose at the end a new approach (the equivalence approach) for teaching linear equations. Thus, the equivalence approach points out the meanings of the variable as a placeholder, as a meaningless symbol, and as an unknown; it presents algebraic expressions as objects and explains the concept of equivalent expressions and then the concept of equivalent equations. Besides, the approach has the main objective of providing a new method for solving equations based on the equivalence concept. As revealed from the analysis of the post-test results, and compared to students who were taught using the traditional teaching method, the equivalence approach teaching module was effective in enhancing the students' flexibility in using multiple strategies and selecting the more efficient one in solving equations. Additionally, the students who received the equivalence approach 
teaching method were less likely to make two categories of pattern errors in solving equations: conceptual errors and transformation errors. Finally, it is believed that by devoting more time to the EA course the results will be more interesting and surprising.

However, this study has some limitations that can be the subject of future research. First, the results of the same study with a larger sample size will be much more representative. Second, it is believed that the use of the equivalence approach much earlier, for example to teach students their first learnings about algebraic expressions and equations, will be effective and beneficial. Third and finally, in a quest to better evaluate this new approach, the authors should propose other tasks to examine the effect on the students' conceptual knowledge of equations. For example, to evaluate the students' ability to identify equivalent equations according to their structure.

Author contributions: All authors have sufficiently contributed to the study, and agreed with the results and conclusions.

Funding: This study is supported by the Regional Center for Education and Training Professions in Agadir, and the BenMsik Faculty of Science in Casablanca.

Declaration of interest: No conflict of interest is declared by authors.

Acknowledgements: We wish to thank participating teachers and students of Hassan 2 high school, Casablanca.

\section{REFERENCES}

Baroody, A. J., \& Dowker, A. (Eds.). (2003). The development of arithmetic concepts and skills: Constructing adaptive expertise. Lawrence Erlbaum. https:/ / doi.org/10.4324/9781410607218

Baroody, A. J., Feil, Y., \& Johnson, A. (2007). An alternative reconceptualization of procedural and conceptual knowledge. Journal for Research in Mathematics Education, 38(2), 115-127. https://doi.org/10.2307/30034952

Blöte, A. W., Van der Burg, E., \& Klein, A. S. (2001). Students' flexibility in solving two-digit addition and subtraction problems: Instruction effects. Journal of Educational Psychology, 93(3), 627-638. https:/ / doi.org/10.1037/0022-0663.93.3.627

Brown J., Skow K., \& the IRIS Center. (2016). Mathematics: Identifying and addressing student errors. http:/ /iris.peabody.vanderbilt.edu/case_studies/ ics_matherr.pdf

Byrnes, J. P., \& Wasik, B. A. (1991). Role of conceptual knowledge in mathematical procedural learning. Developmental Psychology, 27(5), 777-786. https:/ / doi.org/10.1037/0012-1649.27.5.777

Crooks, N. M., \& Alibali, M. W. (2014). Defining and measuring conceptual knowledge in mathematics. Developmental Review, 34(4), 344-377. https:/ / doi.org/10.1016/j.dr.2014.10.001
Chi, M. T. H. (2005). Commonsense conceptions of emergent process: Why some misconceptions are robust. The Journal of the Learning Science, 14(2), 161199. https:/ / doi.org/10.1207/s15327809jls1402_1

Hiebert, J., \& Lefevre, P. (1986). Conceptual and procedural knowledge in mathematics: An introduction analysis. In J. Hiebert. (Ed.), Conceptual and procedural knowledge: The case of mathematics (pp. 1-28). Lawrence Erlbaum.

Hiebert, J., \& Capenter, T. P. (1992). Learning and teaching with understanding. In D. A. Grouws (Ed.), Handbook of research on mathematics teaching and learning (pp. 65-97). Macmillan.

Kieran, C. (1981). Concepts associated with the equality symbol. Educational Studies in Mathematics, 12(3), 317-326. https:/ / doi.org/10.1007/BF00311062

Kieran, C. (1992). The learning and teaching of school algebra. In D. A. Grouws (Ed.), Handbook of research on mathematics teaching and learning (pp. 390-419). Macmillan.

Kilpatrick, J., Swafford, J., \& Findell, B. (2001). Adding It Up: Helping Children Learn Mathematics. National Academy Press. https:// doi.org/10.17226/9822

Knuth, E. J., Stephens, A. C., McNeil, N. M., \& Alibali, M. W. (2006). Does Understanding the Equal Sign Matter? Evidence from Solving Equations. Journal for Research in Mathematics Education, 36(4), 297-312. https:/ / doi.org/10.2307/30034852

Li, X. (2006). Cognitive Analysis of students' errors and misconceptions in variables, equations and functions (Doctoral dissertation), Texas A\&M University.

Malle, G. (1993). Didaktische Probleme der elementaren Algebra [Didactic problems in elementary algebra]. Vieweg. https://doi.org/10.1007/978-3-322-895615

McNeil, N. M., \& Alibali, M. W. (2005). Why won't you change your mind? Knowledge of operational patterns hinders learning and performance. Child Development, 76(4), 883-899. https://doi.org/ 10.1111/j.1467-8624.2005.00884.x

National Research Council. (2001). Classroom Assessment and the National Science Education Standards. National Academies Press.

Perry M. (1991). Learning and transfer: Instructional conditions and conceptual change. Cognitive Development, 6(4), 449-468. https:/ / doi.org/10.1016 /0885-2014(91)90049-J

Prediger, S. (2010). How to develop mathematics-forteaching and for understanding: The case of meanings of the equal sign. Journal of Mathematics Teacher Education, 13(1), 73-93. https://doi.org/ 10.1007 / s10857-009-9119-y 
Riccomini, P. J. (2016). How to use math error analysis to improve instruction. In Webinar error analysis to inform instruction. The Pennsylvania State University.

Rittle-Johnson, B., \& Alibali, M. W. (1999). Conceptual and Procedural Knowledge of Mathematics: Does One Lead to the Other?. Journal of Educational Psychology, 91(1), 175-189. https:// doi.org/10.1037 /0022-0663.91.1.175

Sfard, A., \& Linchevski, L. (1994). The gains and the pitfalls of reification: The case of algebra. Educational Studies in Mathematics, 26(2), 191-228. https:/ / doi.org/10.1007/978-94-017-2057-1_4

Sleeman, D. (1984). An attempt to understand students' understanding of basic algebra. Cognitive Science, 8(4), 387-412. https://doi.org/10.1016/S03640213(84)80008-7
Star, J. R. (2005). Reconceptualizing procedural knowledge. Journal for Research in Mathematics Education, 36(5), 404-411. https:/ / doi.org/10.2307/ 30034943

Star, J. R., \& Seifert, C. (2006). The development of flexibility in equation solving. Contemporary Educational Psychology, 31(3), 280-300. https:/ / doi.org/10.1016/j.cedpsych.2005.08.001

Star, J. R., \& Rittle-Johnson, B. (2008). Flexibility in problem solving: The case of equation solving. Learning and Instruction, 18(6), 565-579. https:/ / doi.org/10.1016/j.learninstruc.2007.09.018

Steinberg, R., Sleeman, D., \& Ktorza, D. (1990). Algebra students' knowledge of equivalence of equations. Journal for Research in Mathematics Education, 22(2), 112-121. https:/ / doi.org/10.2307/749588

\section{http://www.ejmste.com}

